them in accordance with CWC requirements and how to do this safely with minimal impact on public health and the environment. The aim of the IUPAC Technical Report is to provide information on the available destruction technologies in order to help countries arrive at appropriate, informed decisions.

Graham S. Pearson was chairman of the IUPAC Working Party which prepared this Technical Report and is a professor of international security in the Department of Peace Studies at the University of Bradford, Bradford, West Yorkshire, United Kingdom. Prior to 1995, he was director-general and chief executive of the Chemical and Biological Defence Establishment at Porton Down, United Kingdom.

Richard S. Magee is vice president of Carmagen Engineering, Inc., Rockaway, New Jersey, USA. He was previously associate provost for Research and Development at the New Jersey Institute of Technology.

in. www.iupac.org/publications/pac/2002/7402/

7402x0187.html

\section{Definitions of Basic Terms Relating to Polymer Liquid Crystals (IUPAC Recommendations 2001)}

by M. Barón and R. F. T. Stepto

Pure and Applied Chemistry, Vol. 74, No. 3, pp. 493509 (2002)

This document provides definitions of the basic terms that are used in the field of liquid-crystalline polymers. It is the result of extensive discussions and evaluations by the former Commission of Macromolecular Nomenclature. It was produced with the cooperation and advice of representatives of the International Liquid Crystal Society.

The recommendations concern terminology relating to the structure of liquid-crystalline polymers. In view of the rapid growth of the field, the terms defined have been restricted to those presently in common usage. They have been selected from the recently published comprehensive document "Definitions of Basic Terms Relating to LowMolar-Mass and Polymer Liquid Crystals" [(Pure and Applied Chemistry, 73(5) 845-895 (2001)].

The recommendations are intended to form a readily usable guide for the reader interested in the structural description of polymer liquid crystals. The more comprehensive document (vide supra) should be used for terminology associated with mesophases and the optical textures and physical characteristics of liquid-crystalline materials. The numbering of terms in the document is consistent within itself and cross-references are made to the numbering of terms in the more comprehensive document.

The document contains the following sections: introduction, general definitions, and liquid-crystalline poly- mers. It also contains a reference list and an alphabetical index of terms that serves as a subject index. The general definitions section gives the definitions of 27 principal terms and some subsidiary terms concerned mainly with the types of mesophase and types of mesogen; one example is reproduced below. The section dealing specifically with liquid-crystalline polymers defines 12 terms and gives 21 structural examples.

\section{7 [2.10] mesogenic group, mesogenic unit, mesogenic moiety}

A part of a molecule or macromolecule endowed with sufficient anisotropy in both attractive and repulsive forces to contribute strongly to mesophase or, in particular, LC mesophase formation in low-molar-mass and polymeric substances.

Notes:

1."Mesogenic "is an adjective that in the present document applies to molecular moieties that are structurally compatible with the formation of LC phases by the molecular system in which they exist.

2.Mesogenic groups occur in both low-molar-mass and polymeric compounds.

3.A majority of mesogenic groups consists of rigid rodor disc-like molecular moieties.

Examples
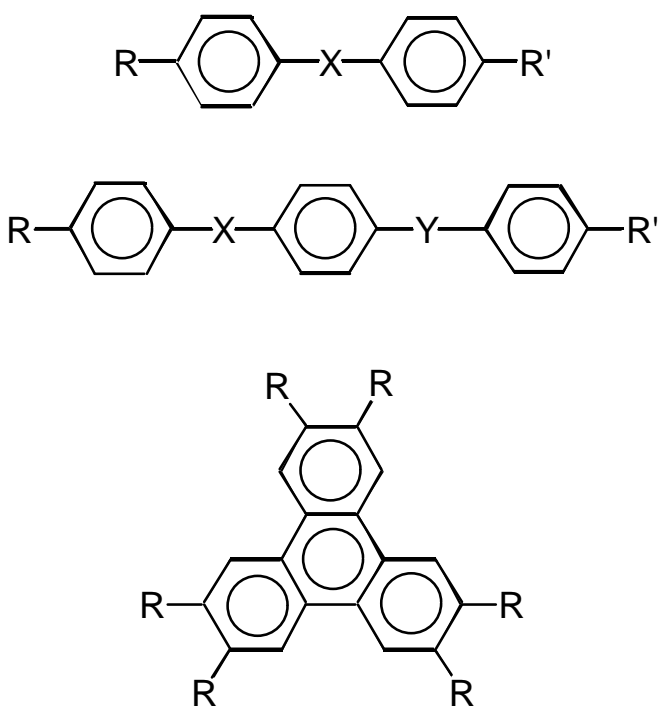

where $X$ and $Y$ are covalent bonds or linking units such as:

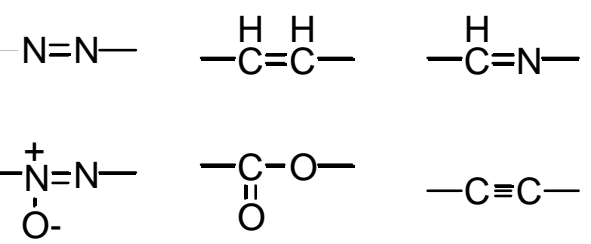

www.iupac.org/publications/pac/2002/7403/ 7403x0493.html 


\section{Dos and Don'ts-Tips of ICTNS \\ On Quantity Calculus}

Each symbol of a quantity (single letter italic) in an equation stands for the value of the quantity, which is

$$
\text { (quantity) }=\text { (numerical value) } \times \text { (unit) }
$$

In this way the equations hold for any units as we believe the laws of nature should. Units are a matter of human choice, and no law in nature should depend on it.

Thus

or with symbols

$$
\text { force }=\text { mass } \times \text { acceleration }
$$

$$
\mathrm{F}=\mathrm{m} \mathrm{a}
$$

irrespective of what units we choose.

\section{Equations should be written in a form not implying certain units.}

In applications with many repetitive calculations it is often convenient to write equations with numerical values in certain units. Then, however, different symbols should be used.

Equation (2) can for a certain purpose be written in the form

$$
\{F\}_{N}=\{m\}_{\mathrm{kg}} \cdot\{a\}_{\mathrm{m} \mathrm{s}}{ }^{2}
$$

or

$$
\frac{\mathrm{F}}{\mathrm{N}}=\frac{\mathrm{m}}{\mathrm{kg}} \cdot \frac{\mathrm{a}}{\mathrm{ms}^{-2}}
$$

where $\{\mathrm{F}\}_{\mathrm{N}}=\mathrm{F} / \mathrm{N}$ is the numerical value of the force in newtons, etc. Eq. (3) can be derived from (2) by division of both sides by $\mathrm{N}=\mathrm{kg} \mathrm{m} \mathrm{s}^{-2}$.

If we measure the mass in pounds and acceleration in inches per second squared and we are still interested in the force in newtons, we can divide equation (2) by (lb in s-2) $=0.545 \mathrm{~kg}$. $0.0254 \mathrm{~m} \mathrm{~s}^{-2}=0.0115 \mathrm{~N}$ obtaining

or in a more convenient form

$$
\frac{F}{0.0115 N}=\frac{m}{1 b} \cdot \frac{a}{\text { in } s^{-2}}
$$

$$
\frac{\mathrm{F}}{\mathrm{N}}=86.7 \frac{\mathrm{m}}{\mathrm{Tb}} \cdot \frac{\mathrm{a}}{\text { in }^{-2}}
$$

This is also the way in which we would write computer programs. However, this does not mean that we are allowed to write

$$
\mathrm{F}=86.7 \mathrm{~m} \mathrm{a}
$$

which obviously only holds if the symbols denote numerical values of quantities in a special choice of units. Even worse, if mass happens to be $1 \mathrm{lb}$ always in our experiments, this does not allow us to write

$$
\mathrm{F}=86.7 \mathrm{a}
$$

See also: Quantities, U nits and Symbols in Physical Chemistry, 2nd edition (The Green Book), I. Mills, T. Cvitas, K. Homann, N. Kallay, and K. Kuchitsu, Blackwell Science, 1993 [ISBN 0-63203-5838] 